\title{
Evapotranspiration modelling at large scale using near-real time MSG SEVIRI derived data
}

\author{
N. Ghilain, A. Arboleda, and F. Gellens-Meulenberghs \\ Royal Meteorological Institute, Brussels, Belgium \\ Received: 14 July 2010 - Published in Hydrol. Earth Syst. Sci. Discuss.: 20 September 2010 \\ Revised: 10 January 2011 - Accepted: 8 February 2011 - Published: 4 March 2011
}

\begin{abstract}
We present an evapotranspiration (ET) model developed in the framework of the EUMETSAT "Satellite Application Facility" (SAF) on Land Surface Analysis (LSA). The model is a simplified Soil-VegetationAtmosphere Transfer (SVAT) scheme that uses as input a combination of remote sensed data and atmospheric model outputs. The inputs based on remote sensing are LSASAF products: the Albedo (AL), the Downwelling Surface Shortwave Flux (DSSF) and the Downwelling Surface Longwave Flux (DSLF). They are available with the spatial resolution of the MSG SEVIRI instrument. ET maps covering the whole MSG field of view are produced from the model every $30 \mathrm{~min}$, in near-real-time, for all weather conditions. This paper presents the adopted methodology and a set of validation results. The model quality is evaluated in two ways. First, ET results are compared with ground observations (from CarboEurope and national weather services), for different land cover types, over a full vegetation cycle in the Northern Hemisphere in 2007. This validation shows that the model is able to reproduce the observed ET temporal evolution from the diurnal to annual time scales for the temperate climate zones: the mean bias is less than $0.02 \mathrm{~mm} \mathrm{~h}^{-1}$ and the root-mean square error is between 0.06 and $0.10 \mathrm{~mm} \mathrm{~h}^{-1}$. Then, ET model outputs are compared with those from the European Centre for Medium-Range Weather Forecasts (ECMWF) and the Global Land Data Assimilation System (GLDAS). From this comparison, a high spatial correlation is noted, between 80 to $90 \%$, around midday. Nevertheless, some discrepancies are also observed and are due to the different input variables and parameterisations used.
\end{abstract}

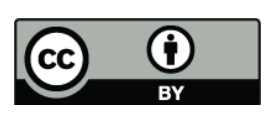

Correspondence to:

F. Gellens-Meulenberghs

(f.meulenberghs@meteo.be)

\section{Introduction}

Evapotranspiration (ET) is an important component of the water cycle, and is directly connected to the surface energy budget. However, as ET cannot be observed directly at large (regional to continental) scale, it is still poorly known today (Dolman and de Jeu, 2010). A correct quantification of ET would contribute to a better knowledge of the water cycle and to an improved ability to quantify future changes in water cycle variables. Therefore, in order to palliate the lack of observations, ET models are developed. However, large uncertainties remain on the temporal evolution and spatial repartition of ET, and especially over land surface (see for example Boone et al., 2009). The Global Energy and Water Experiment (GEWEX) of the World Climate Research Program has been concentrating its efforts for many years on this issue. In particular LandFlux (Wood et al., 2010), a recent initiative of the GEWEX Radiation Panel, is tasked to set up global data sets of multi-decadal surface turbulent fluxes.

Although ET cannot be observed directly at large scale, remote sensing techniques offer increasing possibilities to characterise land surfaces at the regional scale and are able to provide useful input to a variety of ET models. Different techniques to assess ET using remote sensing (see Courault et al., 2005; Kalma et al., 2008; Li et al., 2009), from simple empirical relationships (e.g. Wang et al., 2007) to the most complex models (e.g. Rodell et al., 2004; Albergel et al., 2010) have been investigated and applied to a variety of spatial scales, from local and regional (Bastiaanssen et al., 1998; $\mathrm{Su}, 2002$; Stisen et al., 2008; Miglietta et al., 2009) to global scales (Jiménez et al., 2009). Most of these studies are made for research purposes and use only selected datasets.

Recently, new developments have been made in order to obtain operationally ET estimates based on remote sensing, both at continental and global scales. These new monitoring tools exploit either polar or geostationary satellite data. The MODIS instrument, on-board Terra and Aqua is used to

Published by Copernicus Publications on behalf of the European Geosciences Union. 
provide 8-days ET estimates at the global scale (Mu et al., 2007). WACMOS (Su et al., 2010; http://wacmos.itc.nl/), a recent initiative of ESA in collaboration with GEWEX, is currently developing a new global ET product (Timmermans et al., 2010) based on SEBS model (Su, 2002; Su et al., 2007) and on AATSR and MERIS sensors, both on-board the ENVISAT satellite. These new monitoring tools make use of polar orbiting satellite data. These satellites provide images with a high spatial resolution, but have the disadvantage of a low observation frequency (of the order of one observation per day, or less, for a given site). Consequently, these studies have to rely on interpolations in order to fill observation gaps and on the hypothesis of a constant evaporation fraction during the day, an approximation as, in practice, a diurnal variation exists (Lhomme and Elguero, 1999; Gentine et al., 2007). On the other hand, geostationary satellites provide images at continental scale with lower spatial resolution but a very high observation rates (with one observation every $30 \mathrm{~min}$, or even $15 \mathrm{~min}$, in the case of METEOSAT satellites). This high observation frequency is particularly interesting to monitor quickly evolving variables as a function of diurnal cycle and cloudiness. Precursor work has been made by Rosema (1993) to assess ET with METEOSAT satellite. Over the United States, GOES thermal sensor is exploited to provide hourly and daily ET estimates (Anderson et al., 2007). Other works in the same direction are on-going in Europe in the framework of the Global Monitoring for Environment and Security (GMES), in particular through the Geoland project.

The purpose of the present work is to present an ET operational model, relying on geostationary satellite data, which provides half-hourly ET in near-real time, over Europe, Africa and a part of South America. This work is developed in the framework of the EUMETSAT's "Land Surface Analysis - Satellite Application Facility" (LSA-SAF) (Trigo et al., 2011; http://landsaf.meteo.pt/), of which the objective is to develop algorithms for the estimation of operational land products using meteorological satellites. Main input data is derived from the SEVIRI instrument, on-board Meteosat Second Generation (MSG) satellites. This satellite has a $3 \mathrm{~km}$ spatial resolution at sub-satellite point, located at $0^{\circ}$ latitude above the equator, and has a high observation repetition rate $(15 \mathrm{~min})$.

An important characteristic of the study is that it proposes ET estimates for all weather conditions. Therefore, the model provides continuous ET times series, useful for further applications. Contrarily to most studies (Kalma et al., 2008), we do not use Land Surface Temperature (LST) as a mandatory input of the model for an all-weather evaluation of ET, because model evaluation would be restricted to cloud free sky conditions. Alternatively, the methodology developed here follows as a baseline the parameterizations used in Soil-Vegetation-Atmosphere Transfer (SVAT) schemes.

Validation is an important activity for models targeting an offer of operational products. Therefore, an important part of this paper focuses on the model validation. Comparison with in-situ observations at local scale is a direct way to assess the quality of the ET model output. We therefore compare the model results with observations from CarboEurope and European stations from national weather services in Europe. Investigations of model behaviour at regional scale are beneficial to ensure good spatial estimation. However, validation at larger scale is still hardly possible, because of the lack of observations at this scale. Consequently, we compare the results with two operational models that provide ET at global scale, ECMWF and GLDAS (Rodell et al., 2004). This comparison is carried on over the whole MSG field of view.

This paper is organised as follows. The model formulation and its use in the context of LSA-SAF are presented (Sect. 2) and are followed by a short description of the LSA-SAF ET product (Sect. 3). Comparison with in-situ observations at local scale in Europe is the subject of Sect. 4. We present in Sect. 5 the results of the comparison with ECMWF and GLDAS. We finally discuss the results and draw conclusions and guidelines for future research directions (Sects. 6 and 7).

\section{Methodology}

In this section, we consider successively the model formulation, the used forcing data, as well as the operational implementation of the model in the context of LSA-SAF.

\subsection{Model}

The proposed model includes relationships classically used in SVAT models. We choose specific parameterizations from the TESSEL SVAT scheme (van den Hurk et al., 2000; Balsamo et al., 2009) as a baseline for model development, with a few variants in the formulation (see description below). The algorithm is then adapted to accept real-time data from meteorological satellites as forcing (Gellens-Meulenberghs et al., 2007).

The basic spatial unit for the model is called 'pixel', in reference to the elementary unit of the sensor onboard the meteorological satellites. The model provides output directly at this scale. However, depending on the location of the pixel, different types of vegetation can share the area. A decomposition of the pixel surface is done by considering the fraction fully covered by vegetation and the remaining fraction of bare soil for each land cover. The considered smaller homogeneous entities (vegetation or bare soil) are called "tiles". Then, the set of equations of the model is solved for each tile before spatially averaging at the pixel level.

The sensible $H_{i}$ and latent $L E_{i}$ heat fluxes are computed for each tile $i$ using the classical bulk relationships

$$
H_{i}=\frac{\rho}{r_{\mathrm{a}, i}}\left[c_{p}\left(T_{\mathrm{sk}, i}-T_{\mathrm{a}}\right)-g z_{\mathrm{a}}\right]
$$

and 


$$
L E_{i}=\frac{L_{v} \rho}{\left(r_{\mathrm{a}, i}+r_{\mathrm{s}, i}\right)}\left[q_{\mathrm{sat}}\left(T_{\mathrm{sk}, i}\right)-q_{\mathrm{a}}\left(T_{\mathrm{a}}\right)\right]
$$

with $\rho$ the air density, $r_{\mathrm{a}, i}$ the aerodynamic resistance, $c_{p}$ the heat capacity at constant pressure, $T_{\mathrm{sk}, i}$ the surface "skin" temperature, $T_{\mathrm{a}}$ the air temperature at level $z_{\mathrm{a}}$ above the surface, $g$ the acceleration due to gravity, $L_{\mathrm{V}}$ the latent heat of vaporisation, $r_{\mathrm{s}, i}$ the stomatal resistance, $q_{\mathrm{a}}$ the air specific humidity at height $z_{\mathrm{a}}$ and $q_{\text {sat }}$ the value of the surface specific humidity at saturation. The aerodynamic resistance $r_{\mathrm{a}, i}$ is computed as a function of the atmospheric stability following Monin-Obukhov similarity theory (Brutsaert, 1982)

$$
\frac{1}{r_{\mathrm{a}, i}}=\frac{k u_{* i}}{\ln \left(\frac{z_{\mathrm{a}}-d_{i}}{z_{0 h, i}}\right)-\Psi_{h}\left(\frac{z_{\mathrm{a}}-d_{i}}{L_{i}}\right)+\Psi_{h}\left(\frac{z_{0 h, i}}{L_{i}}\right)}
$$

with friction velocity given by

$$
u_{* i}=\frac{k u}{\ln \left(\frac{z-d_{i}}{z_{0 m, i}}\right)-\Psi_{m}\left(\frac{z-d_{i}}{L_{i}}\right)+\Psi_{m}\left(\frac{z_{0 m, i}}{L_{i}}\right)}
$$

and Monin-Obukhov stability parameter computed as

$$
L_{i}=\frac{\rho u_{* i}^{3}}{k g\left(\frac{H_{i}}{c_{p} T_{a}}+0.608 \frac{L E_{i}}{L_{v}}\right)}
$$

In Eqs. (3) to (5), $k$ is the von Kármán constant $(k=0.40)$, $u_{\mathrm{a}}$ is the wind speed at height $z$ above the surface, $\Psi_{h}$ and $\Psi_{m}$ are respectively the sensible heat and momentum stability functions (Beljaars and Viterbo, 1994), $d_{i}$ is the displacement height, $z_{0 h, i}$ and $z_{0 m, i}$ are respectively the roughness lengths related to sensible and momentum fluxes. The stomatal resistance is obtained following the Jarvis (1976) approach adopted in ECMWF TESSEL SVAT scheme (Viterbo and Beljaars, 1995; van den Hurk et al., 2000). For vegetation, the general formulation is given by

$r_{s, i}=\frac{r_{s} \min , i}{\mathrm{LAI}_{i}} f_{1}(S \downarrow) f_{2}(\bar{w}) f_{3}\left(\delta q_{\mathrm{a}}\right)$

where $r_{s} \min , i$ is the minimum stomatal resistance, $\mathrm{LAI}_{i}$ is the leaf area index, $\bar{w}$ is the average unfrozen soil water content, $\delta q_{\mathrm{a}}$ is atmospheric air moisture deficit and $f_{1}$ to $f_{3}$ are the Jarvis functions.

For the particular case of bare ground, a simplified formulation is used

$r_{s, i}=r_{s \min , i} f_{2}\left(w_{1}\right)$

with $w_{1}$ being the unfrozen soil water content in first soil layer. In Eqs. (6) and (7) TESSEL parameterizations and parameters values are adopted, excepted $r_{s}$ min, $i$ and $\mathrm{LAI}_{i}$. Monthly $\mathrm{LAI}_{i}$ values are used as well as related parameterizations for displacement height $\left(d_{i}\right)$ and roughness lengths $\left(z_{0 m, i}, z_{0 h, i}\right)$ according to Masson et al. (2003). Adopted values for $r_{s} \min , i$ are listed in Table 1 .
At tile level $i$, the surface energy budget, acting as a constraint on surface heat fluxes, is expressed by

$R n_{i}-H_{i}-L E_{i}-G_{i}=0$

where $R n_{i}$ is the net radiation at the surface and $G_{i}$ is the ground heat flux. In Eq. (8) all fluxes, excepted $R n_{i}$, are computed positively upward.

Net radiation is given by

$R n_{i}=(1-\alpha) S \downarrow+\varepsilon\left(L \downarrow-\sigma T_{\mathrm{sk}, i}^{4}\right)$

where $\alpha$ is the albedo, $S \downarrow$ is the downwelling surface short wave flux (DSSF), $\varepsilon$ is the emissivity, $L \downarrow$ is the downwelling surface longwave flux (DSLF), $\sigma$ is the Stefan-Boltzmann constant and $T_{\mathrm{sk}, i}$ is the skin temperature. This latter is the model variable representing the surface temperature at tile level. It acts as an aerodynamic temperature in Eq. (1) and is used to estimate surface thermal emission in Eq. (9). In the above expression, $R n_{i}, S \downarrow, L \downarrow$, are counted positively downward.

As a second constraint, the ground heat flux is approximated by

$G_{i}=\beta_{i} R n_{i}$

the method of Chehbouni et al. (1996) being adopted to derive $\beta_{i}$ from $\mathrm{LAI}_{i}$.

The system to be solved is composed of four non-linear Eqs. (1), (2), (4), (8) with four unknowns $\left(H_{i}, L E_{i}, T_{\mathrm{sk}, i}\right.$ and $\left.u_{* i}\right)$. Given the non-linear interdependency between the unknowns, an iterative procedure is used to solve the system taking relationships (3), (5) to (7), (9) and (10) into account. Neutral stability is assumed as initial condition. Iteration is stopped when pixel estimates of latent and sensible heat fluxes are numerically stabilized. In particular a modelled surface or "skin" temperature is computed from Eqs. (1), (2) and (9).

The averaged LE flux at pixel level is given by

$L E=\sum \zeta_{i} L E_{i}$

where $\zeta_{i}$ and $L E_{i}$ are respectively the coverage fraction and the latent heat flux of tile $i$ in the considered pixel. For vegetation, $\zeta_{i}$ is the fraction occupied by a land cover type in the pixel, which only the fraction covered by vegetation has been kept. The land cover types associated to tiles (grassland, crops, forests, bare soil, etc.), the respective coverage fraction $\zeta_{i}$ and associated parameters are deduced from the ECOCLIMAP land cover database (Masson et al., 2003).

The evapotranspiration flux $E\left[\mathrm{~kg} \mathrm{~m}^{-2} \mathrm{~s}^{-1}\right]$ at pixel level is associated to the latent heat flux $L E\left[\mathrm{~W} \mathrm{~m}^{-2}\right]$ through

$E=L E / L_{v}$

with $L_{\mathrm{V}}$ the latent heat of vaporisation $\left[\mathrm{J} \mathrm{kg}^{-1}\right]$ computed as

$L_{v}=\left[2.501-0.00234\left(T_{a}-273.15\right)\right] 10^{6}$ 

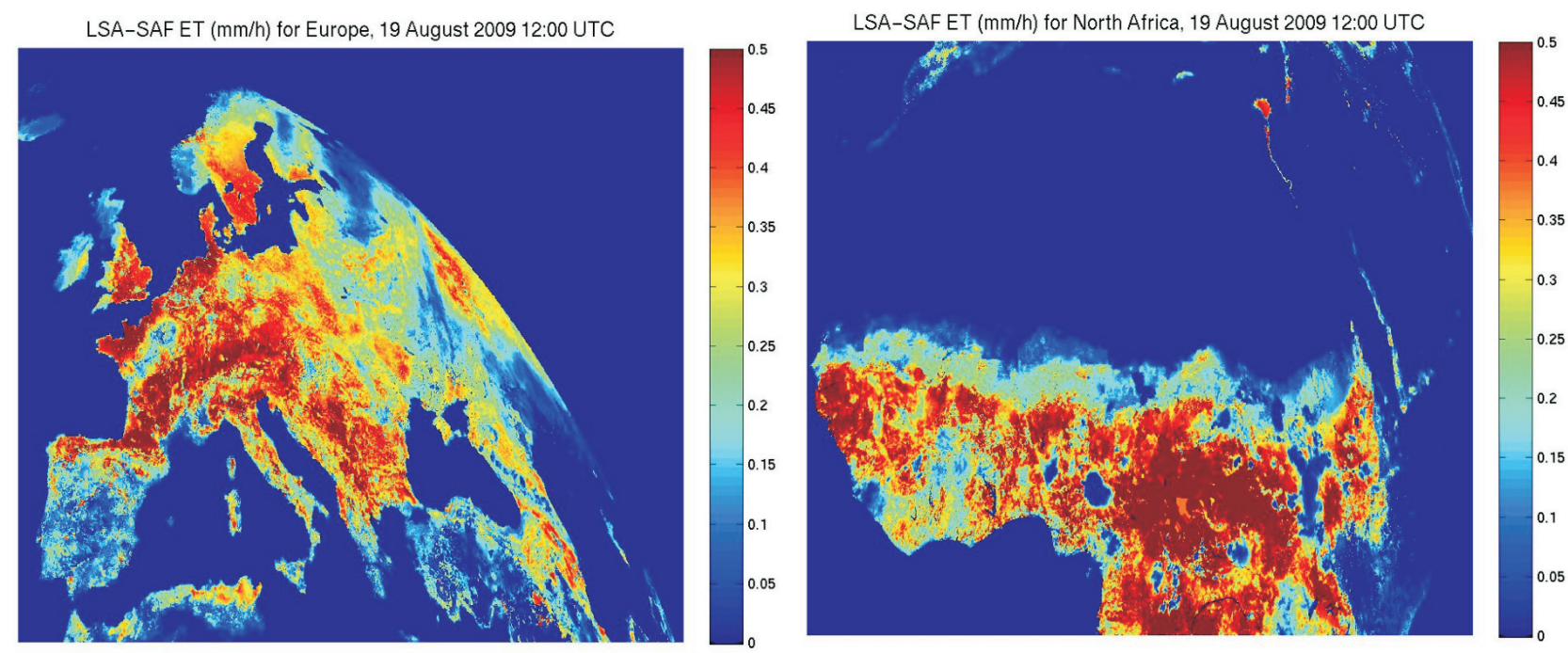

Fig. 1. LSA-SAF ET (mm/h) over Europe (left) and North Africa (right) on 19 August 2009 at 12:00 UTC.

Table 1. Vegetation types and associated minimum stomatal resistance $\left(r_{s \min , i}\right)$.

\begin{tabular}{lll}
\hline$i$ & Vegetation type & $r_{s \min , i}\left[\mathrm{~s} \mathrm{~m}^{-1}\right]$ \\
\hline 1 & Bare soil & 50 \\
2 & Snow & NA \\
3 & Deciduous Broadleaved Trees & 300 \\
4 & Evergreen Needleleaved Trees & 250 \\
5 & Evergreen Broadleaved Trees & 250 \\
6 & Crops & 180 \\
7 & Irrigated crops & 180 \\
8 & Grass & 110 \\
9 & Bogs and Marshes & 250 \\
\hline
\end{tabular}

$T_{\mathrm{a}}$ being the air temperature $[\mathrm{K}]$ at the height $z_{\mathrm{a}}$ above the surface. In the above expressions, all fluxes are expressed in $\mathrm{W} \mathrm{m}^{-2}$.

The model presented here can be seen as a simplified SVAT scheme, because soil moisture variation is not explicitly modelled but is provided by an external source. This version of the ET model is currently running in near real time at the LSA-SAF host institute producing ET results over the full MSG disk with a time step of $30 \mathrm{~min}$. More details on the practical implementation of the model are given in the next section.

The model described in this section is referred by the acronym "MET" (for "MSG ET") in the text. To check ability of the model to reproduce ET observations in a variety of biomes under different climatic conditions, the model has been first forced in off-line mode with local observations. Results of this verification are presented in Appendix A.

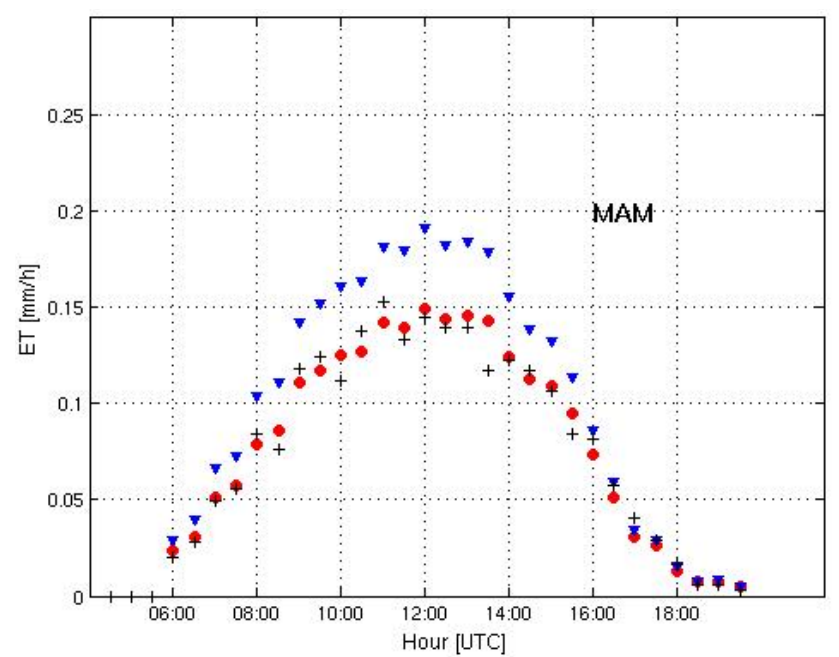

Fig. 2. Mean seasonal diurnal cycle of ET for the CarboEurope-IP Vielsalm station for March to May (MAM) 2007. Observation (+), pixel (v) and "tile" (o) estimate from LSA-SAF MET.

\subsection{Forcing data and practical algorithm implementation}

In the context of EUMETSAT LSA-SAF, the evapotranspiration model is forced with data derived from MSG SEVIRI instrument. The daily Albedo, $\alpha$, (Geiger et al., 2008a; Carrer et al., 2010) and half-hourly short-wave $S \downarrow$ (Geiger et al., 2008b) and long-wave $L \downarrow$ (Ineichen et al., 2009) surface fluxes are the main forcing for MET model. In this way, we insure that short term fluctuations related to cloudiness variations as well as diurnal and annual radiation cycles are taken into account. 
Table 2. Used flux stations for validation. Network (Net): Royal Meteorological Institute of Belgium (RMI), Koninklijk Nederland Meteorologische Instituut (KNMI), CarboEurope (CarboEur). North Latitude (Lat), East Longitude (Long). Biome types: mixed forest (MF), evergreen needle leaf forest (ENF), deciduous broadleaf forest (DBF), grassland (G). Elevation (Alt) of the site above sea level. Climate: temperate (Temp), Mediterranean (Med). Reference (Ref).

\begin{tabular}{llrrllll}
\hline Station (country) & Net & Lat (deg) & Long (deg) & Biome & Climate & Alt (m) & Ref \\
\hline Buzenol (B) & RMI & 46.62 & 5.59 & G & Temp. & 320 & Gellens-Meulenberghs (2005) \\
Cabauw (NL) & KNMI & 51.97 & 4.93 & G & Temp. & 0 & Beljaars and Bosveld (1997) \\
Tojal (PT) & CarboEur & 38.48 & -8.02 & G & Med. & 190 & Peireira et al. (2007) \\
Hesse (FR) & CarboEur & 48.67 & 7.07 & DBF & Temp. & 300 & Granier et al. (2000) \\
Wetzstein (DE) & CarboEur & 50.45 & 11.46 & ENF & Temp. & 785 & Rebmann et al. (2010) \\
Vielsalm (B) & CarboEur & 50.30 & 6.00 & MF & Temp. & 450 & Aubinet et al. (2001) \\
\hline
\end{tabular}

ECOCLIMAP (Masson et al., 2003) provides the model with the land cover at $1 \mathrm{~km}$ resolution and vegetation parameters required in SVAT models, i.e. $\mathrm{LAI}_{i}, \zeta_{i}, z_{0 m, i}, z_{0 h, i}$. In addition, the emissivity $\varepsilon$ used in the presented model is the monthly emissivity provided by the ECOCLIMAP database (ranging from 0.96 for bare soil to 0.99 for fully vegetated surfaces). In addition to the land cover classification in 215 ecosystems, the database provides a decomposition of each ecosystem into vegetation types, or tiles listed in Table 1. We adapted ECOCLIMAP, such as it could be used by our model. First, ECOCLIMAP is projected onto the grid defined by SEVIRI. ECOCLIMAP must then be obtained at a coarser spatial resolution. The number of vegetation tiles in each pixel is limited to three and monthly vegetation parameters are used. ECOCLIMAP provides the monthly coverage fraction of vegetation $\left(\right.$ fveg $\left._{i}\right)$ for each tile and the fractions $\xi_{i}$ covered by vegetation compared to bare soil. The model considers separately the contribution from vegetated parts and parts of soil exposed to direct radiation. The energy balance is performed on each of the 3 dominant vegetated fractions (i.e. $\zeta_{i}=$ fveg $_{i} \xi_{i}$ ) plus on the bare soil fraction of the pixel (i.e. $\zeta_{i}=1-\sum\left(\right.$ fveg $\left.\left._{i} \xi_{i}\right)\right)$.

In operational mode, meteorological variables are preprocessed by the LSA-SAF computer system. Forecasts fields corresponding to $12 \mathrm{~h}-24 \mathrm{~h}$ term $0.5^{\circ} \times 0.5^{\circ}$ are projected and spatially interpolated onto the MSG grid. Air and dew point temperatures at $2 \mathrm{~m}, 10$-m wind speed, surface atmospheric pressure, soil moisture and temperature in the 4 soil layers, reinitialized twice a day by the ECMWF 4DVAR analysis process, are retrieved. Nearest neighbour is used as interpolation scheme except for temperatures for which a bicubic interpolation is implemented. Dew point temperature, air temperature and air pressure are used to calculate air specific humidity needed in Eq. (2). Soil moisture and soil temperature allow computing the liquid fraction of soil water content $\bar{w}$ in the root-zone and in the superficial soil layer $\mathrm{w}_{1}$ in Eqs. (6) and (7), following van den Hurk et al. (2000). The meteorological fields are then linearly interpolated to $30 \mathrm{~min}$ time steps from their original tri-hourly values.

\section{LSA-SAF ET product}

The presented model is used to produce data files corresponding to land surface evapotranspiration estimates over the areas covered by MSG. The evapotranspiration product, ET, is generated in near-real-time every $30 \mathrm{~min}$, using the latest available information from MSG SEVIRI instrument and ECMWF forecasts. Data files and quality flags are produced for the full MSG grid divided in 4 sub regions (Europe, North Africa, South Africa and South America). Figure 1 provides an example for the 19 August 2009 at 12:00 UTC for Europe and North Africa. A full ET product description is detailed in LSA-SAF Product User Manual (LSA-SAF, 2010).

Registered users have free access to LSA-SAF ET results over full disk through LSA-SAF web site (see http://landsaf. meteo.pt/) or via EUMETCast (http://www.eumetsat.int/ Home/Main/DataAccess/EUMETCast/index.htm) dissemination. Registered beta-users can access earlier results (from new model versions) through LSA-SAF ftp site. By interacting with the development team, users can contribute to improve the results or better adapt the proposed products to their specific needs.

\section{In-situ validation}

The MET model has been validated over Europe. We present here the results obtained from the comparison of the model with in-situ surface flux data from ground measurement stations. The surface fluxes have been provided by the CarboEurope network (Baldocchi et al., 2001), and local networks of national weather services (Table 2). Five measurement stations are situated in temperate climate zones, while another is located in a Mediterranean environment. Three types of temperate forest are represented in this validation, as well as Mediterranean and temperate grasslands. Lack in energy balance closure with the eddy correlation technique, as used in FLUXNET, has been shown to lead to uncertainty on fluxes measurement around 20\% (Wilson et al., 2002). Therefore, possible accuracy limitation will be considered 

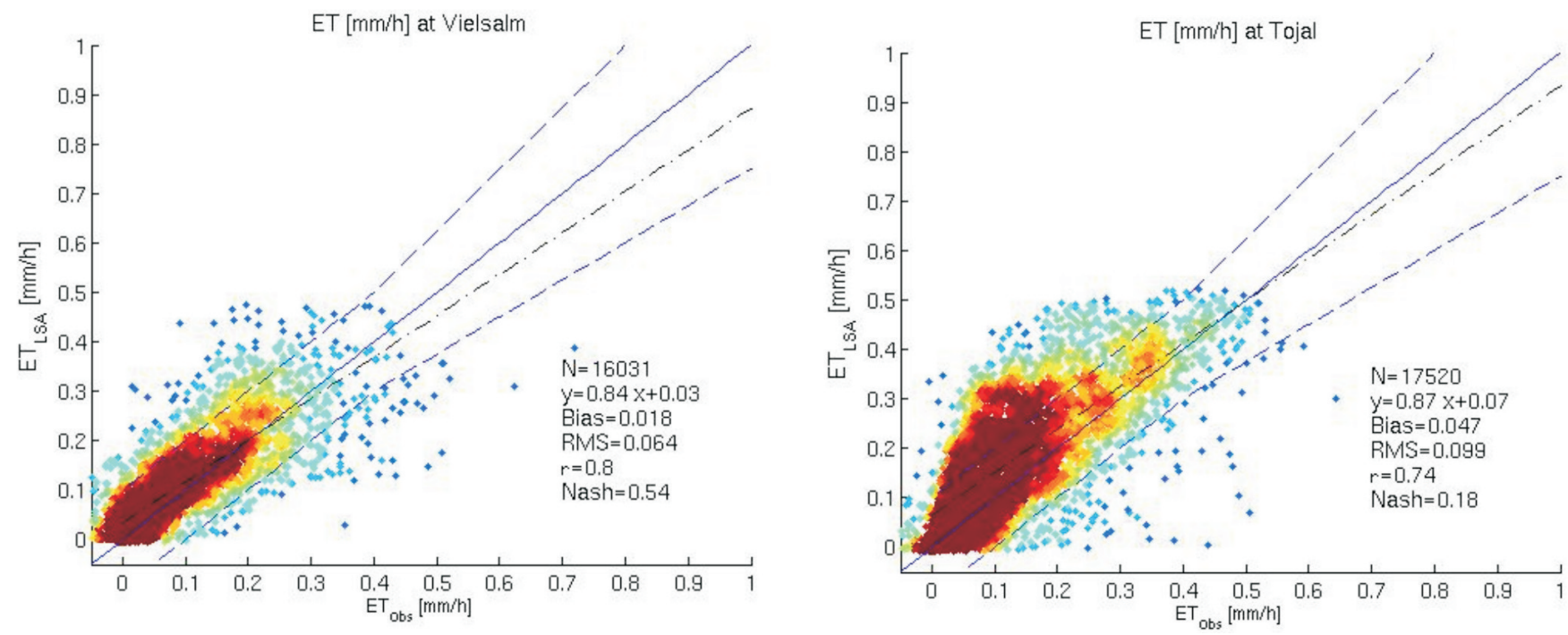

Fig. 3. Comparison between $30 \mathrm{~min}$ LSA-SAF ET $\left(\mathrm{mm} \mathrm{h}^{-1}\right)$ and observations at (left) Vielsalm FLUXNET station (Belgium) and (right) Tojal (Portugal). Period: March to November 2007. Dashed line: envelop associated to PRD criteria (see text); straight line: 1:1 line; Dashdoted line: linear regression line.

Table 3. Comparison between LSA-SAF ET and observed ET at validation stations: statistical results $\left(\right.$ Bias $\left[\mathrm{mm} \mathrm{h}^{-1}\right]$, RMS $[\mathrm{mm}$ $\mathrm{h}^{-1}$ ], correlation coefficient (Corr), Nash index, PRD criterion (see text) [\%]); vegetation type: Grassland (G), Deciduous Broadleaved Forest (DBF), Evergreen Needleleaved Forest (ENF), Mixed Forest (MF).

\begin{tabular}{lrrrrrr}
\hline Station & $\begin{array}{r}\text { Vegetation } \\
\text { Type }\end{array}$ & Bias & RMS & Corr & Nash & PRD \\
\hline Buzenol & G & 0.02 & 0.10 & 0.81 & 0.51 & 80.1 \\
Cabauw & G & 0.02 & 0.07 & 0.90 & 0.66 & 90.1 \\
Tojal & G & 0.05 & 0.10 & 0.74 & 0.18 & 59.9 \\
Hesse & DBF & 0.00 & 0.09 & 0.56 & 0.31 & 89.9 \\
Wetzstein & ENF & -0.02 & 0.08 & 0.79 & 0.59 & 87.9 \\
Vielsalm & MF & 0.02 & 0.06 & 0.80 & 0.54 & 88.2 \\
\hline
\end{tabular}

by comparison to a quality criterion defined at the end of this section. However, it should be underline that the good standardisation of the measurement technique over the entire FLUXNET network enables to do comparisons with measurements in a uniform way.

We consider the period spanning from 1 March to 31 December 2007. This period is particularly relevant for Europe, because it includes a whole vegetation cycle and, in the same time, the periods for which the evaporation demands are the largest, due to the solar forcing. At Hesse station, there was no data available for 2007 , instead, comparisons were performed with data from 1 May to 30 June 2006, which includes the entire period of canopy development.

In the comparison of the ET variable the direct result of the model, corresponding to the pixel level estimation, is not used. Indeed, the pixel ET estimate could be very different from in-situ measurements if the pixel encompasses other vegetation types than the measurement target. In Europe, in particular, landscapes are fragmented a lot, and one MSG pixel is usually composed of different vegetation types. An example for March to May 2007 over a forest site in Belgium (Fig. 2) shows that the pixel mean seasonal diurnal cycle of ET is larger than observed. However, the tile estimate, corresponding to the targeted vegetation type, reproduces the right diurnal cycle. This is explained by the occurrence in the MSG pixel of large grassland patches that are exposed to higher evaporation demand during that period. Therefore, to allow a meaningful comparison with ground measurements, the operational procedure systematically forces the model to output the ET estimate at the tile level for a set of validation stations location. We select then ET for the tile that corresponds to the vegetation type representative of the local measurements.

In Table 3, we present the statistical results obtained from the comparison with the half-hourly measurements for the selected stations. All ET estimates are expressed in $\mathrm{mm}$ $\mathrm{h}^{-1}$. Four statistical indices are tabulated for each dataset: the global bias, the root mean square error (RMS), the correlation coefficient and the Nash index (Nash and Suttcliffe, 1970), which definition is given in Eq. (14) and a short interpretation can be found in Albergel et al. (2010):

$$
\text { Nash }=1-\frac{\sum_{i=1}^{n}\left(y_{i \text { est }}-y_{i \mathrm{obs}}\right)^{2}}{\sum_{i=1}^{n}\left(y_{i \mathrm{obs}}-\overline{y_{i \mathrm{obs}}}\right)^{2}}
$$


Table 4. Summary of models characteristics and output used for inter-comparison.

\begin{tabular}{lll}
\hline & ECMWF & GLDAS \\
\hline Versioning & Cycle 31r1 & GLDAS/ \\
& & Noah 2.7.1. \\
Land Surface Scheme & TESSEL & Noah \\
Coupled to atmosphere & Yes & No \\
Domain & Global & Global \\
Horizontal spatial resolution & 0.25 & $1^{\circ}$ \\
Available temporal resolution & $3 \mathrm{~h}$ & $3 \mathrm{~h}$ \\
Land Cover Used & IGBP & University \\
& & of Maryland \\
\hline
\end{tabular}

where $y_{i \text { est }}$ and $y_{i \text { obs }}$ are respectively estimated and observed values, $\overline{y_{i \text { obs }}}$ is the mean of observations and $n$ is the sample size.

As well, a density scatter plot is shown in Fig. 3 for Vielsalm and Tojal, allowing an easy visualization of the statistical results. Bias is low, not exceeding $0.2 \mathrm{~mm} \mathrm{~h}^{-1}$ excepted for Tojal, indicating that on the long term, the mean ET computed is consistent with in-situ measurements. The RMS shows a fairly good capture of the short temporal scale dynamics by the model. At last, the correlation coefficient indicates that the model used in the context of remote sensing is able to reproduce the global temporal dynamics of evapotranspiration, at least for four of the datasets, with a correlation coefficient at 0.8 or above. For Hesse, however, the correlation coefficient is lower. A possible explanation is that the actual evolution of the canopy does not match with the monthly vegetation indices used. The behaviour of ET variations is consequently affected on this short period. This conclusion is reinforced in view of the good results obtained in Table A2 for Hesse. At Tojal, representative of a drier environment, the correlation coefficient, equal to 0.74 , is lower than in the other stations. A close analysis allows us to incriminate for a part of the year the soil moisture used as input for this location (see Sect. 6). The Nash-Sutcliff indices summarise the scores obtained through different statistical indices, and are given in Table 3. Scores above 0.50 are found for four of the six stations. Low scores are obtained for Hesse (0.31) and for Tojal (0.18), in agreement with the above mentioned observations.

Fairly good results have been obtained from this validation, showing that the model is able to reproduce the global patterns observed at local scale. However, it also shows the limitation of such validation methodology. Even if the correlation coefficient is fairly high, it will intrinsically not reach scores as in point-wise simulation using observed data as input (as in Appendix A) because the spatial scale differs between local scale measurements and meso-scale simulation of the model using SEVIRI derived data. Because of this
Table 5. Spatial correlation between the mean $\Delta \% \mathrm{ET}$ and the mean of (1) $\Delta \% \mathrm{LAI} / r_{s} \min$, (2) $\Delta \mathrm{CVH}$ and (3) $\Delta \% S \downarrow$ for North and South Africa (see text).

\begin{tabular}{ccccc}
\hline & & $\Delta \% \mathrm{LAI} / r_{s} \min$ & $\Delta \mathrm{CVH}$ & $\Delta \% S \downarrow$ \\
\hline \multirow{2}{*}{ NAfr } & MET-ECMWF & 0.31 & 0.12 & 0.42 \\
& MET-GLDAS & -0.02 & 0.19 & 0.48 \\
SAfr & MET-ECMWF & 0.54 & 0.01 & 0.65 \\
& MET-GLDAS & -0.09 & 0.10 & 0.38 \\
\hline
\end{tabular}

limitation, and considering experimental uncertainty on observations, we introduce a quality criterion called "Product Requirement on Data quality" (PRD). This can be applied uniformly on all model output whatever the particular case of each station can be regarding data accuracy and possible energy imbalance. The PRD index is defined to score the rate of good estimations of the ET model given accuracy of reference observed measurements and with respect to expected accuracy for possible applications with MET results. To be considered as good the error should be less than $25 \%$ for the highest day time ET values. We selected a threshold of $0.4 \mathrm{~mm} \mathrm{~h}^{-1}$ for this purpose. For other cases (night time, winter, morning and evening values), we adopt an absolute criteria: if ET is less than $0.4 \mathrm{~mm} \mathrm{~h}^{-1}$, then the error on ET should be less than $0.1 \mathrm{~mm} \mathrm{~h}^{-1}$. This quality criterion can be visualised on the scatterplots of Fig. 3, as dashed lines forming an envelope for good quality estimates. Overall results are also listed in Table 3. Using this score index, we obtain very good rates for all stations (from 80 to $90 \%$ ), excepted for Tojal, where it reaches only $60 \%$.

\section{Intercomparison with ECMWF and GLDAS ET}

To complement the validation against local ground measurements, we additionally compare MET output to other existing products available operationally at regional scale. While the intercomparison is not a formal assessment of the MET capabilities compared to standard measurement techniques, it shows, however, if MET produces estimates within a similar range. For that purpose, ECMWF forecasts and GLDAS data (Rodell et al., 2004) are used to compare results at the regional scale. The main characteristics of these data products are listed in Table 4.

The intercomparison is achieved for the period from April to November 2007 (from March for the European area). In order to achieve a consistent analysis of the results, LSASAF ET has been projected in latitude-longitude on a common grid with a coarser spatial resolution $\left(1^{\circ} \times 1^{\circ}\right)$. Three maps per day are then produced by averaging ET rates over three successive periods of three hours each: P1 covers the time interval from $09: 00$ to $12: 00$ UTC, P2 from 12:00 to 15:00 UTC and P3 from 15:00 to 18:00 UTC. 

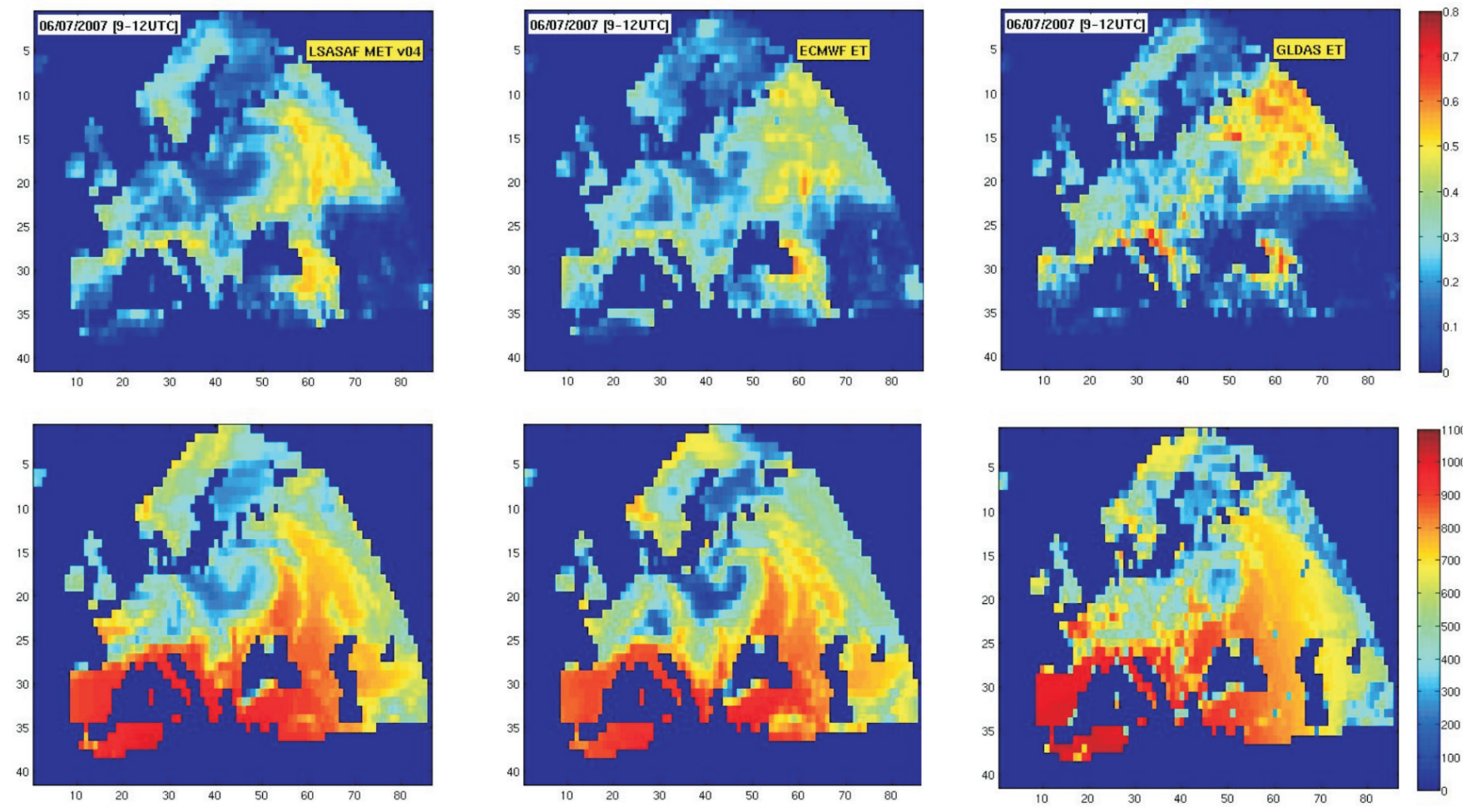

Fig. 4. Comparison of LSA-SAF (left), ECMWF (middle) and GLDAS (right) ET (top) and global radiation (bottom), 3-hourly averages (09:00 to 12:00 UTC, excepted GLDAS global radiation: instantaneous 12:00 UTC) for the 6 July 2007.

\subsection{Intercomparison results}

Figure 4 illustrates on a test case (Europe, 6 July 2007, P1) how the three model estimates compare. The corresponding surface short-wave downward radiation used as forcing is displayed as well. Note here that the tri-hourly GLDAS $\mathrm{S} \downarrow$ was not available and that the instantaneous flux at 12:00 UTC is displayed instead for a visual interpretation. On this test case, similar values range and spatial patterns are easily recognisable. However, it clearly appears on a closer look that the three models do not give the same results and that large regional differences occur. Differences in $\mathrm{S} \downarrow$ input could explain some differences in ET. However, it is also noticeable that it should not be the sole explanation. Interpretation of the differences will be discussed later.

After this example, we compare the results globally by means of three different statistical approaches: crosscorrelation, monthly mean occurrence distribution, and spatial distribution of the mean difference over the total period.

First, we compute spatial correlation between pairs of images by considering LSA SAF MET images and successively ECMWF and GLDAS ET images. Figure 5 displays the correlation evolution, for time periods P1 to P3 over Europe, between LSA-SAF ET and ET forecasts from ECMWF on one hand, and with GLDAS ET images on the other hand.
The computed spatial correlation between images is nearly constant for P1 and P2, with a correlation generally above $90 \%$. For P3, a seasonal effect with a good correlation for March to September and a decreasing correlation during autumn is due to the progressive change from day to night, implying less contrast in ET images when ET drops to zero. For the summer months, image correlation is slightly better with ECMWF than with GLDAS for P1 and P2. This observation confirms that the general patterns characterising European ET maps, like meteorological and land cover effects, are found in both products. However, better correlation with GLDAS is observed for P3 towards the end of the considered period. Similarly to Europe, spatial correlation between MET and ECMWF ET and GLDAS ET is computed for the 3 other geographical windows for the mid-day periods, $\mathrm{P} 1$ and P2 for Africa, P2 and P3 for South America. Spatial correlation is higher than $80 \%$ in Africa and 90\% in South America. Correlation values obtained with ECMWF and GLDAS are similar, indicating that the three outputs agree on the general patterns of ET variations.

As second step, we compare the monthly mean distributions of ET estimates produced by the three models. The mean distributions of P1 ET for July 2007, as well as their mean values (vertical bar) are represented for the 4 geographical areas covered by MSG (Fig. 6). The mean distributions of the three model output have comparable 

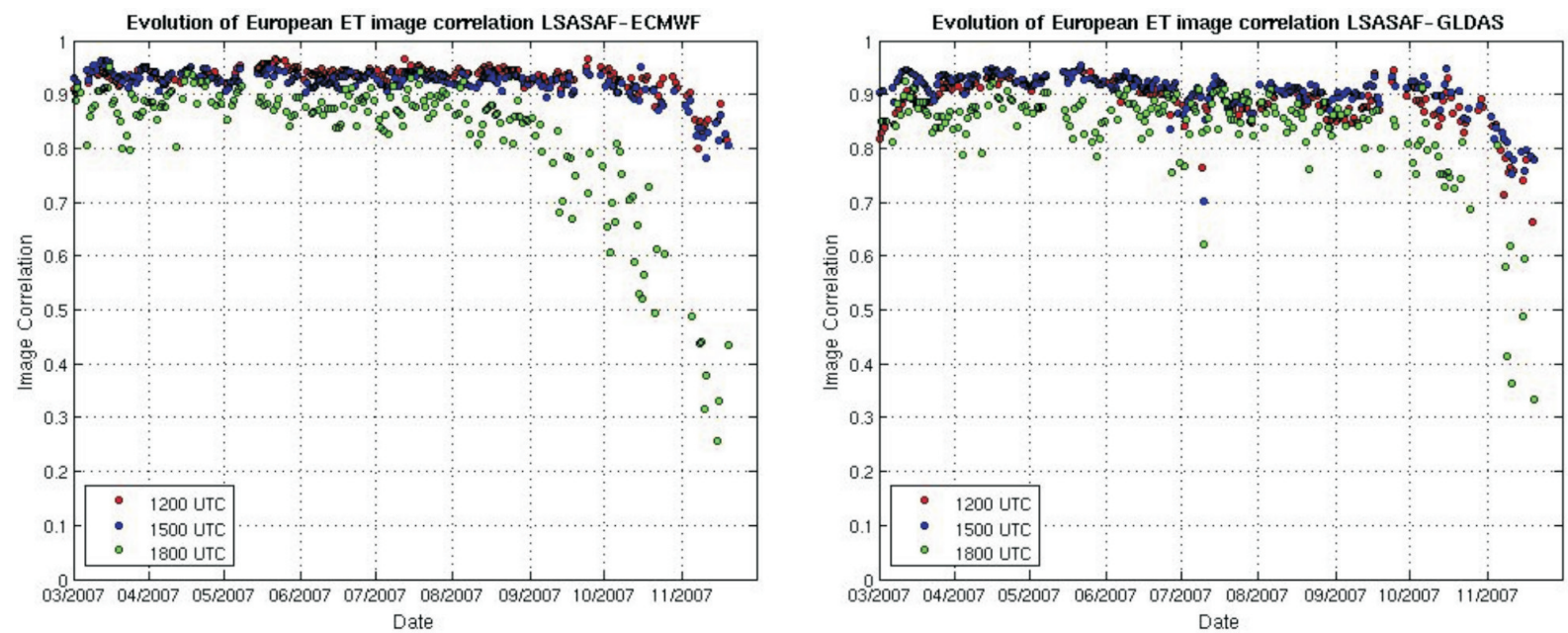

Fig. 5. Evolution of 3-hourly mean image correlation over MSG European window between LSA-SAF ET and ET ECMWF forecasts (left), and with GLDAS ET images (right), from March to November 2007.
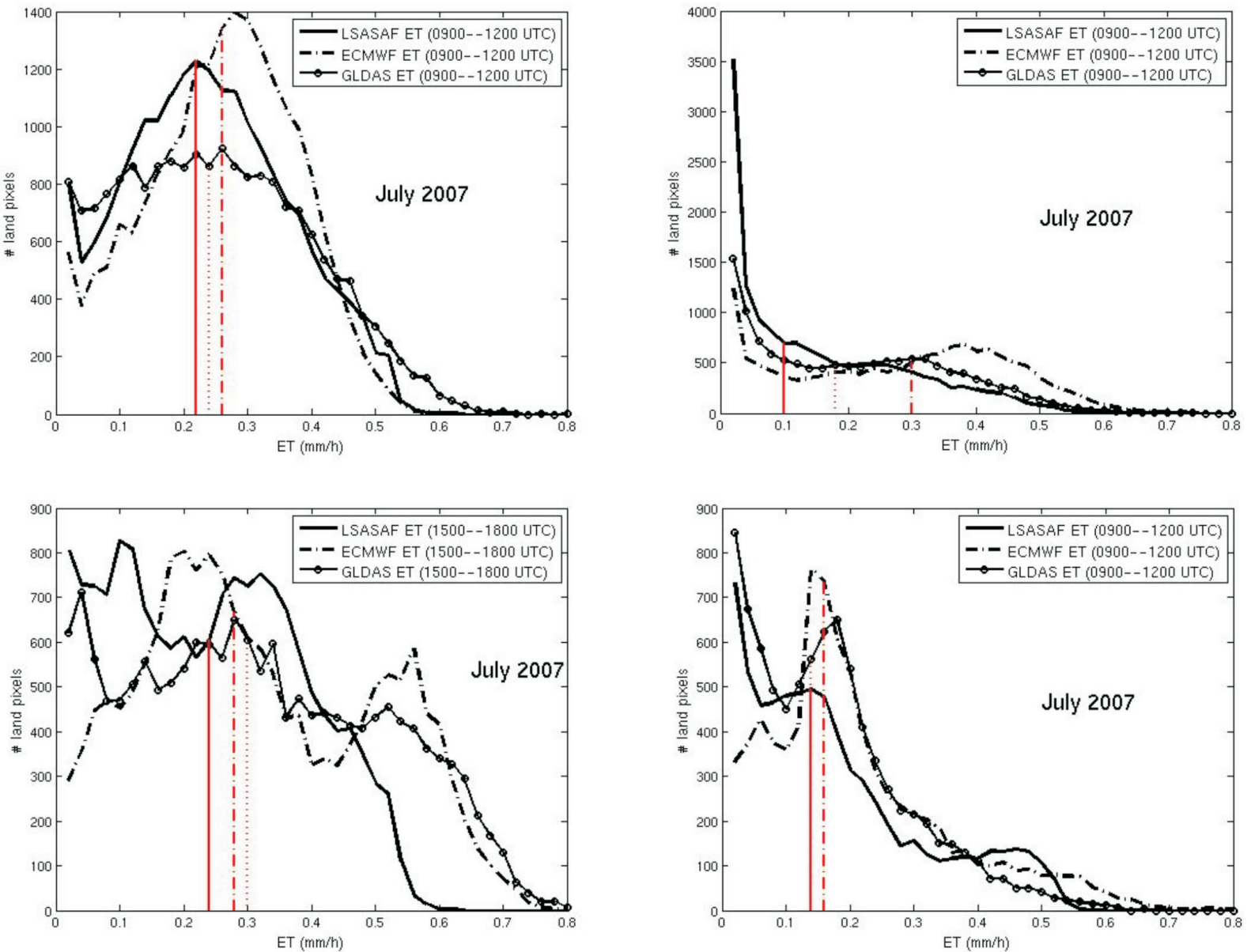

Fig. 6. Distributions of ET estimates from LSA-SAF (solid line), ECMWF (dash-dotted line) and GLDAS (solid line and circles). Each figure encompasses the mean distribution of the 3 hourly averaged ET (09:00 to 12:00 UTC) for July 2007, as well as the mean values of the distributions (vertical lines). Europe (upper left), North of Africa (upper right), South of America (lower left), South of Africa (lower right). 

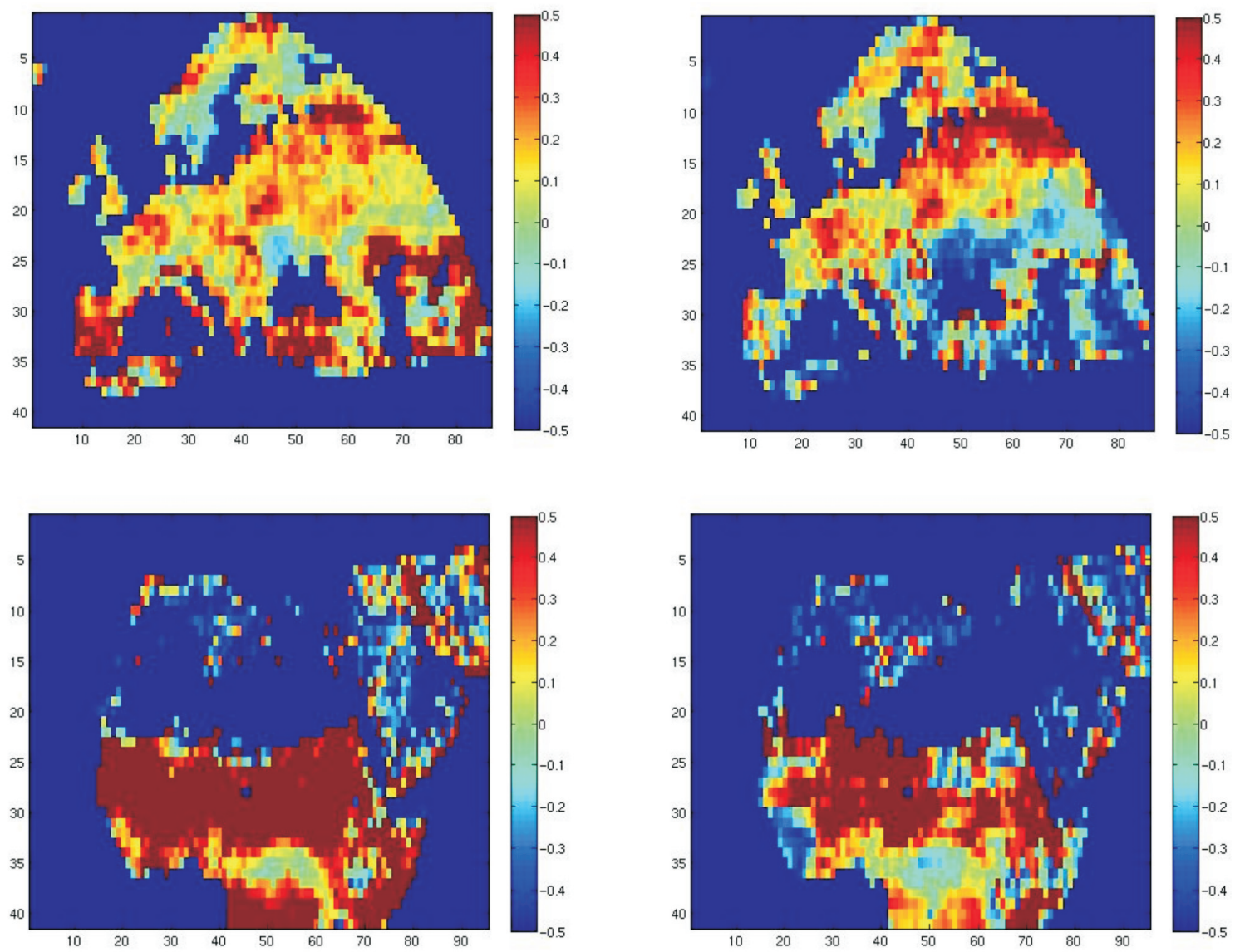

Fig. 7. $1^{\circ} \times 1^{\circ}$ maps of bias between ECMWF ET and LSA SAF MET (left) and between GLDAS and LSA SAF MET (right) over the whole period of inter-comparison. Europe (upper part), North of Africa (lower part).

shape and magnitude, except for South America. The comparison of the means shows slight differences for Europe and South Africa. However, we find larger differences for South America and Northern Africa. For both, LSA SAF MET estimates are globally lesser than ECMWF and GLDAS estimates. For South America, the right tail of the LSA SAF MET distribution indicates a small occurrence of high ET values contrarily to ECMWF and GLDAS. Note that those observations are valid for the other months of the year (not shown).

At last, we examine, pixel-wise, the mean difference of the time series. Maps of the differences over the whole comparison period allow detecting where the models diverge. Figure 7 illustrates the bias between ECMWF and LSA SAF MET and between GLDAS and LSA SAF MET over the whole period of inter-comparison. Maps are presented for Europe and North Africa. To show clearly the differences, a relative bias to the mean MET values has been chosen as metrics. Positive bias means ECMWF or GLDAS exhibits larger estimates than LSA SAF MET. Local differences between the three model outputs are clearly visible. The highest differences occur in some parts of Southern Europe and around the Sahara desert. For Southern Africa (not shown), conclusions are similar to Northern Africa with less differences and a better correspondence between MET and GLDAS, than between MET and ECMWF. As for Northern Africa, the larger differences are found in dry regions with low evaporation rate close to deserts.

\subsection{Intercomparison interpretation}

Despite the good correlation between the three models ET estimates shown in Sect. 5.1, discrepancies are observed. There are three possible sources of differences that could be considered here to explain them: input variables of the respective models, model formulation and model parameters. The three models are based on the similar formulation, with some differences in model paramerizations, but involving comparable model parameters types. One of the most sensitive parameters of these models is the parameter that determines the maximum transpiration rate a vegetation type can bear, i.e. $r_{s} \min$. In the same way, information from vegetation database influences the surface fluxes calculation. The Leaf Area Index (LAI) is crucial because it scales the $r_{s}$ min at 

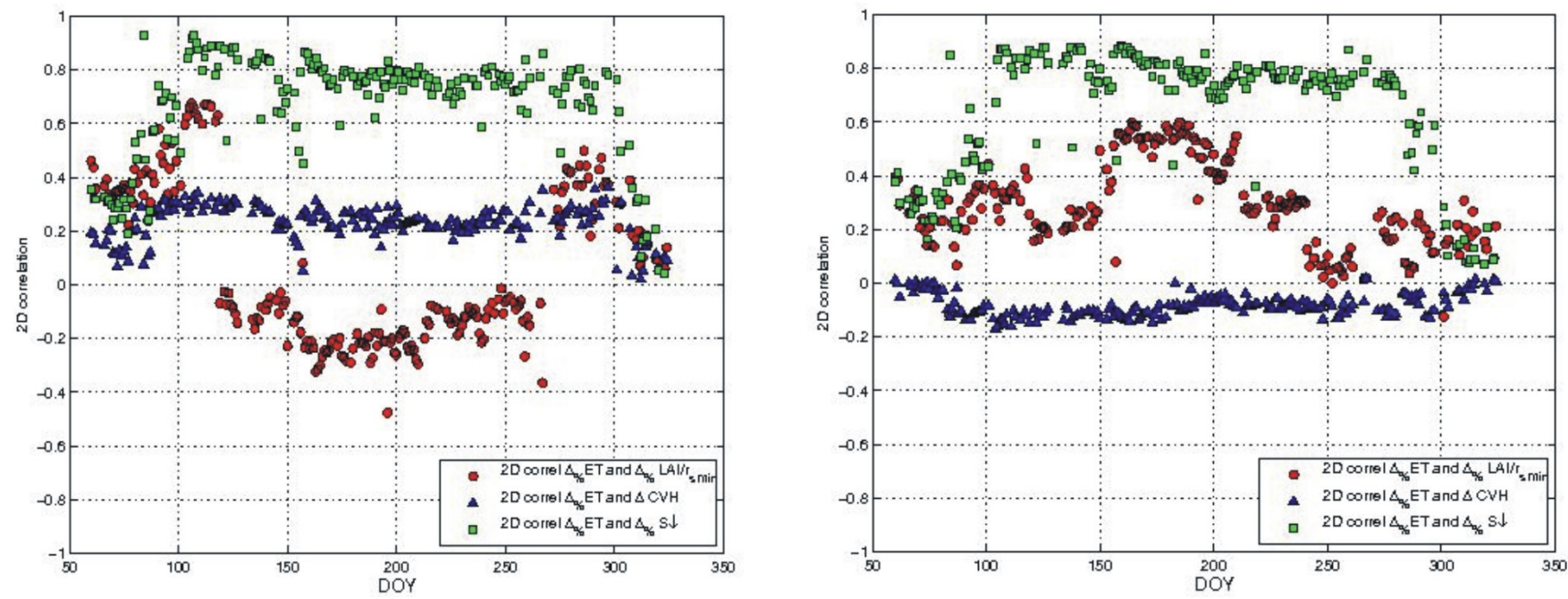

Fig. 8. Spatial (2-D) correlation over Europe between the ET mean relative bias (based on the images between 09:00 to 12:00 UTC) and model differences: (1) $\mathrm{LAI} / r_{s}$ min (red diamonds), (2) High vegetation percentage (CVH, blue triangles), and (3) $S \downarrow$ mean relative bias (DSSF, green squares). At left: comparison between LSA SAF MET and ECMWF. At right: comparison between LSA SAF MET and GLDAS.

model spatial resolution. Therefore, as the ratio $r_{s} \min /$ LAI is explicitly used in the three models (used in Eq. (6) in the present study), we choose it as one of the major potential sources of discrepancies. Furthermore, since the evaporative fraction is quite different for forests than grass or crops, land cover, and more particularly the fraction of high and low vegetation, is one very important field that needs to be considered in such study. Land cover is by consequence chosen as another possible source of ET differences between the models. At last, focusing on meteorological fields used as input, $S \downarrow$ is one of the most sensitive input of the models. Three motivations are considered here: (1) $S \downarrow$ is presumably the main driver of the global behavior of ET in the temperate regions (Teuling et al., 2009), (2) $S \downarrow$, related to cloudiness, is difficult to predict accurately in numerical weather forecast models, and (3) it can be different for each model considered here, as it consists in weather forecasts (for ECMWF and GLDAS) and in LSA-SAF DSSF (for the MET model). $S \downarrow$ is therefore considered as a third major possible source of ET differences. Other model differences could have been investigated, such as air temperature or soil moisture. However, as MET is forced by both the air temperature and the soil moisture forecasted by the ECMWF atmospheric model, we have only chosen in our present analysis variables that are different for the three models. The three envisaged candidates to explain ET discrepancies are (1) differences of $S \downarrow$ input in the models, (2) the land cover and, more specially the difference in high vegetation percentage (CVH), and (3) difference in the ratio $\mathrm{LAI} / r_{s} \mathrm{~min}$. In the following paragraph, $\Delta \% \operatorname{Var}$ denotes the mean relative bias in the variable Var, that can be ET, $S \downarrow$ or LAI $/ r_{s}$ min. The absolute difference in high vegetation percentage is noted $\triangle \mathrm{CVH}$. In order to evaluate the impact of the three possible causes on ET, we calculate time series of spatial correlation between $\Delta \%$ ET and (1) $\Delta \% S \downarrow$, (2) $\Delta \% \mathrm{LAI} / r_{s}$ min and (3) $\Delta \mathrm{CVH}$. The period P1 is used in the following for Europe, North and South Africa. As shown in Fig. 8, for Europe, correlation suggests that solar radiation be the main source of ET difference, as expected, especially outside winter. $\Delta \% \mathrm{LAI} / r_{s} \min$ is indicated as the second main source of ET differences, notably by comparison with GLDAS with a positive correlation all along the year. The time series show an important seasonal behaviour in the case of the comparison with ECMWF: the correlation is positive ( 0.2 to 0.6$)$ in spring and autumn and negative the rest of the year. Solar radiation affects ET at all temporal scales, at the shorter considered time steps and globally. $\Delta \%$ $\mathrm{LAI} / r_{s}$ min biases ET estimates most at short and medium range with ECMWF, and on all time scales with GLDAS. As regards land cover, difference with GLDAS shows no correlation with ET differences, while with ECMWF, it exhibits a weak constant correlation ( 0.2 to 0.3 ).

The above investigations were extended to North and South Africa. The correlations computed over the whole period are given in Table 5. Figures with correlation time series over Africa are not shown: the information is globally redundant with results of Table 5 or otherwise stated. The two major sources of differences between LSA SAF MET and ECMWF ET at daily and annual time scales are $\Delta \% S \downarrow$ and $\Delta \% \mathrm{LAI} / r_{s} \min$. Correlation suggests $\Delta \% S \downarrow$ as the main driver of the differences with GLDAS ET, followed by $\Delta \%$ $\mathrm{LAI} / r_{s} \min$, at short time scale, and by $\Delta \mathrm{CVH}$ over the entire period. A weak seasonal cycle, between -0.2 and 0.2 , is observed (not shown) in the correlation with $\Delta \% \mathrm{LAI} / r_{s}$ min. This cycle in 2-D correlation could explain why $\Delta \%$ ET is 

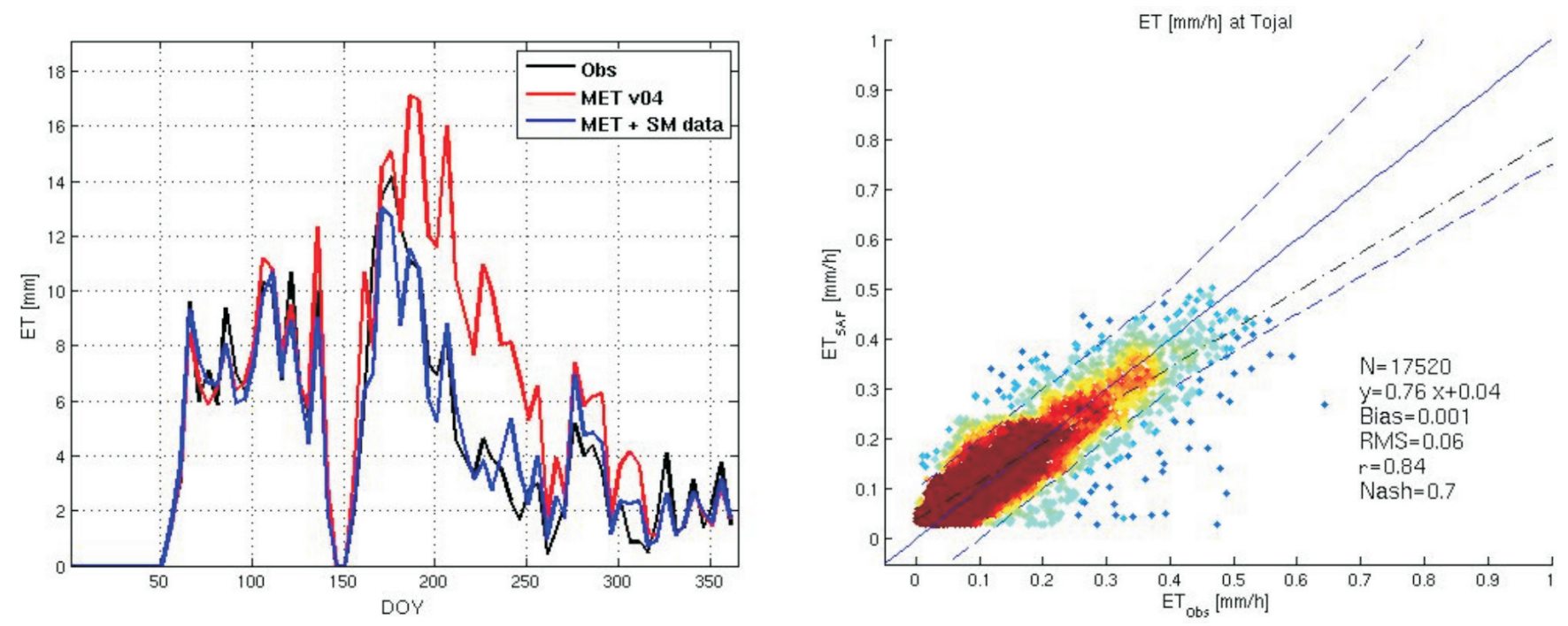

Fig. 9. Left: time series of the 5-days cumulated ET measured (black) and modelled (red) for the CarboEurope-IP Tojal station (Portugal) for the period from March to November 2007 as provided by LSA SAF MET. Modelled ET using soil moisture measured at the station (blue) has been superimposed. Right (as in Fig. 3) but modelled ET computed with soil moisture measured at the station compared to 30 min mean observed ET.

not sensitive to $\Delta \% \mathrm{LAI} / r_{s}$ min at the annual time scale, in the comparison with GLDAS.

To summarize, we have shown that, there is a high spatial correlations between the three investigated models. The ET differences could be due to (1) differences in radiation fluxes used as forcing, (2) differences in land covers and (3) differences in parameterizations, in particular values adopted for the ratio $r_{s} \min , i / \mathrm{LAI}_{i}$ in Eq. (6). The correlations computed suggest that $S \downarrow$ differences be the most influential on ET differences. $\mathrm{LAI} / r_{s}$ min is the second envisaged source of difference between models in magnitude. Differences with GLDAS ET could have also been explained with soil moisture discrepancies between models, especially in the (semi-) arid areas. However, when the water availability for ET is low, $\Delta \% \mathrm{LAI} / r_{s}$ min tend to amplify the observed $\Delta \% \mathrm{ET}$, because it is a very sensitive model parameter in such conditions, making difficult the separation of both effects.

\section{Discussion}

As stated in Sect. 4, the lower scores obtained at Tojal incriminate the soil moisture input for this location. The initial coarser resolution of the ECMWF forecasts is a possible explanation: the soil moisture used in MET model differs from the actual one. By replacing the ECMWF soil moisture forecasts by the actual observations of soil moisture in a pointwise simulation of MET model, we show that the results of the comparison are clearly improved, with a correlation coefficient of 0.84 , a bias almost equal to zero and a RMS of 0.06. The 5-days averaged ET dynamics is clearly improved (Fig. 9, left part and comparison between Figs. 3 and
9, right parts). The Tojal case indicates that using ECMWF soil moisture forecasts as input of MET model may lead to erroneous ET estimates.

Such result encourages continuing research to particularly investigate model quality in driest regions of the world and to further improve the results globally. Soil moisture input accuracy is one main axe of activity. Different ways are explored simultaneously. First tests show that using an explicit modelling of soil thermal and moisture fluxes are beneficial provided that good quality rainfall rates are available. Improvement in rainfall assessment by remote sensing in the future could be profitable to this approach. Another option is to assimilate into the current model remote sensing products sensitive to soil moisture conditions, like LSA-SAF Land Surface Temperature (Trigo et al., 2008) and ERS/ASCAT SSM (Wagner et al., 1999; Drusch et al., 2009). Vegetation products (Verger et al., 2009) are also considered for this purpose and for refining values of parameters currently derived from the ECOCLIMAP database. In such configurations, benefits of the current method will be conserved but results should be improved thanks to the complementary information provided by additional consolidated remote sensed products.

\section{Conclusions}

The baseline version of the model (MET) is currently running in near-real time in the LSA-SAF operating system, producing half-hourly ET results at continental scale (over Europe, Africa and the Eastern part of South America), at the MSG spatial resolution ( $3 \mathrm{~km}$ at sub-satellite point). The 
Table A1. Flux stations. Network (Net): AmeriFlux (AmFlux), Koninklijk Nederland Meteorologische Instituut (KNMI), Coordinated Energy and water cycle Observations Project (CEOP), CarboEurope (CarboEur), Large-Scale Biosphere-Atmosphere Experiment in Amazonia (LBA). Latitude (Lat), Longitude (Long). Biome types: crops (C), grassland (G), deciduous broadleaf forest (DBF), evergreen needle leaf forest (ENF), evergreen broadleaf forest (EBF). Climate: temperate (Temp), Mediterranean (Med), tropical (Trop). Period (years). Reference (Ref).

\begin{tabular}{llrrllll}
\hline Station & Net & Lat $\left.\left[{ }^{\circ} \mathrm{N}\right]\right)$ & Long $\left[{ }^{\circ} \mathrm{E}\right]$ & Biome & Climate & period & Ref \\
\hline Bondville & AmFlux & 40.00 & -88.29 & $\mathrm{C}$ & Temp. & 2002-2003 & Meyers et al. (2004) \\
Cabauw & KNMI/CEOP & 51.97 & 4.93 & $\mathrm{G}$ & Temp. & $1995-1996$ & Beljaars and Bosveld (1997) \\
Hainich & CarboEur & 51.07 & 10.45 & DBF & Temp. & 2003 & Knohl et al. (2003) \\
Hesse & CarboEur & 48.67 & 7.07 & DBF & Temp. & 1997-1998 & Granier et al. (2000) \\
Le Bray & CarboEur & 44.72 & -0.77 & ENF & Temp. & $1997-1998$ & Porté et al. (2000) \\
Loobos & CarboEur & 52.17 & 5.74 & ENF & Temp. & 2003 & Dolman et al. (1998) \\
Puéchabon & CarboEur & 43.74 & 3.59 & EBF & Med. & 2002-2003 & Joffre et al. (1996) \\
Santarem & LBA/CEOP & -3.02 & -54.97 & EBF & Trop. & 2002-2003 & Goulden et al. (2004) \\
\hline
\end{tabular}

results are produced for all weather conditions. This is particularly useful for applications that need continuous time series of ET and that cannot be limited to cloud free cases. Validation against ground measurements shows that LSA-SAF MET algorithm has high overall performances, at least in temperate regions, and is able to reproduce the temporal evolution of ET, at both diurnal to annual scales. The validation methodology used in this study allows a meaningful comparison by evaluating the model at the tile level. From the inter-comparison with ECMWF and GLDAS ET, we conclude that MET estimates are in a range compatible with those estimates and a spatial correlation between $80 \%$ and 95\% for midday images through the studied period for the whole MSG field of view. For high co-zenithal angles better correlation is found with ECMWF while for low angles (spring/late autumn and morning/evening) with GLDAS. Observed discrepancies between models estimates are in most cases not systematic and can be explained in terms of differences in input variables and model parameterization.

Therefore, good confidence on MET results has been gained through the validation presented. However, assessing the quality of such model is still challenging, and more research is needed to confirm conclusions for all areas. It is why we will extend the validation to full MSG field of view, and, in particular, we must collect sufficient datasets in Africa and in dry climatic zones. In addition, validation supports our operational developments by detecting possible causes of uncertainty in some areas and leading the way towards further improvements. For example, it appears that a potential weakness of the model is the use of ECMWF soil moisture forecasts as input.

Refined versions of MET will be implemented in the LSASAF operational system as soon as on-going research and developments activities can demonstrate any significant improvement in capturing the ET process, applicable over the full MSG disk. Privileged means encompass using additional RS input, related to soil moisture and vegetation, and enhanced modelling capability. Users can access data and documentation from the LSA-SAF web site (http://landsaf. meteo.pt/). Interaction with the authors is welcome to better fit ET product with their requests and, in a general way, to improve the LSA-SAF products in the future.

\section{Appendix A}

\section{Validation of MET algorithm}

Validation of MET model itself is necessary to evaluate the pertinence of the formulation. Therefore, point-wise MET simulations forced by local measurements are compared to surface flux data provided by local ground stations, listed in Table A1. A broad range of climate zones and targeted vegetation types are represented through the validation. MET is forced by local observations, excepted for the soil moisture provided by ECMWF forecasts, and the vegetation indices provided by ECOCLIMAP when local measurements are not available. $\mathrm{L} \downarrow$ is not always available, and, if missing, is computed as prescribed in Stöckli et al. (2008). Results from the comparison of the half-hourly LE, converted to ET by means of Eqs. (12) and (13), are presented in Table A2. Four complementary statistical indices are tabulated for each dataset: the global bias, the root mean square error (RMS), the global correlation coefficient and the Nash index (Nash and Sutcliffe, 1970), see Eq. (14). The lowest scores are obtained at Bondville, Puéchabon and Loobos. For the Puéchabon simulation, ECOCLIMAP database vegetation parameters have been used: the results could be the consequence of an inaccurate capture of the canopy evolution essential dynamics. For Bondville and Loobos, however, the source of discrepancies has to be searched elsewhere, and could be due to unsuitable either soil moisture dynamics from ECMWF or parameters values. Overall, the results show that the model itself is able to reproduce the observed variations of ET, with high correlation coefficients and Nash indexes for most stations of the dataset. 
Table A2. Comparison between half-hourly ET measurements and ET estimates obtained by MET forced with local observations. Bias $\left[\mathrm{mm} \mathrm{h}^{-1}\right]$, RMS [mm h$\left.{ }^{-1}\right]$, correlation coefficient (Corr), Nash index. Out of range (OR) refers to negative Nash index.

\begin{tabular}{lrrrr}
\hline & Bias & RMS & Corr & Nash \\
\hline Bondville & 0.015 & 0.10 & 0.71 & 0.38 \\
Cabauw & 0.014 & 0.06 & 0.91 & 0.78 \\
Hainich & 0.019 & 0.05 & 0.81 & 0.60 \\
Hesse & 0.018 & 0.08 & 0.80 & 0.60 \\
Le Bray & -0.024 & 0.08 & 0.81 & 0.63 \\
Loobos & 0.024 & 0.10 & 0.50 & OR \\
Puéchabon & 0.012 & 0.07 & 0.68 & 0.09 \\
Santarem & 0.013 & 0.14 & 0.76 & 0.56 \\
\hline
\end{tabular}

Acknowledgements. The authors acknowledge ESA and Belgian Science Policy for co-funding this project with EUMETSAT (ESA/Contract Nr. 15066/01/NL/Sfe(IC)).

Thanks are due to all validation data providers from FLUXNET, KNMI and CEOP networks. We are also grateful to ECMWF and GLDAS centres for their model output. We thank in particular Matthew Rodell and Hiroko Kato. We are grateful to Gianpaolo Balsamo (ECMWF) for providing the last version of the TESSEL and H-TESSEL codes. The authors thank Bob Su (editor), Scott Sinclair (reviewer) and one additional anonymous referee for their comments that have been very helpful to improve the quality of the manuscript and the understanding of the present research.

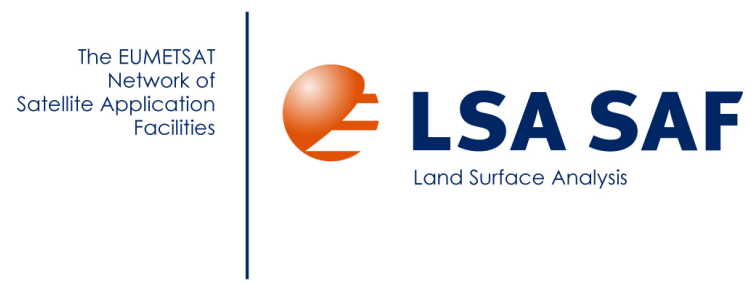

Current work is achieved in the framework of the LSA-SAF.

Edited by: B. Su

\section{References}

Albergel, C., Calvet, J.-C., Mahfouf, J.-F., Rdiger, C., Barbu, A. L., Lafont, S., Roujean, J.-L., Walker, J. P., Crapeau, M., and Wigneron, J.-P.: Monitoring of water and carbon fluxes using a land data assimilation system: a case study for southwestern France, Hydrol. Earth Syst. Sci., 14, 1109-1124, doi:10.5194/hess-14-1109-2010, 2010.

Anderson, M. C., Norman, J. M., Mecikalski, J. R., Otkin, J. A., and Kustas, W. P.: A climatological study of evapotranspiration and moisture stress across the continental United States based on thermal remote sensing: 1. Model formulation, J. Geophys. Res., 112, D10117, doi:10.1029/2006JD007506, 2007.
Aubinet, M., Chermanne, B., Vandenhaute, M., Longdoz, B., Yernaux, M., and Leitat, E.: Long term carbon dioxide exchange above a mixed forest in the Belgian Ardennes, Agr. Forest Meteorol., 108 (4), 293-315, 2001.

Baldocchi, D., Falge, E., Gu, L., Olson, R., Hollinger, D., Running, S., Anthoni, P., Bernhofer, Ch., Davis, K., Evans, R., Fuentes, J., Goldstein, A., Katul, G., Law, B., Lee, X., Mahli, Y., Meyers, T., Munger, W., Oechel, W., Paw, K. T., Pileggard, K., Schmid, H. P., Valentini, R., Verma, S., Vesala, T., Wilson, K., and Wofsy, S.: FLUXNET: A new tool to study the temporal and spatial variability of ecosystem-scale carbon dioxide, water vapor, and energy flux densities, B. Am. Meteorol. Soc., 82 (11), 2415-2434, 2001.

Balsamo, G., Viterbo, P., Beijaars, A., van den Hurk, B., Hirschi, M., Betts, A. K., and Scipal, K.: A revised hydrology for the ECMWF model: Verification from field site to terrestrial water storage and impact in the integrated forecast system, J. Hydrometeorol., 10 (3), 623-643, 2009.

Bastiaanssen, W. G. M., Menenti, M., Feddes, R. A., and Holtslag, A. A. M.: The Surface Energy Balance Algorithm for Land (SEBAL): Part 1 formulation, J. Hydrol., 212-213, 198-212, 1998.

Beljaars, A. C. M. and Bosveld, F. C.: Cabauw data for the validation of land surface parameterization schemes, J. Climate, 10, 1172-1193, 1997.

Beljaars, A. C. M. and Viterbo, P.: The sensitivity of winter evaporation to the formulation of aerodynamic resistance in the ECMWF model, Bound.-Lay. Meteorol., 71 (1-2), 135-149, 1994.

Boone, A., de Rosnay, P., Balsamo, G., Beljaars, A., Chopin, F., Decharme, B., Delire, C., Ducharme, A., Gascoin, S., Grippa, M., Guichard, F., Gusev, Y., Harris, P., Jarlan, L., Kergoat, L., Mougin, E., Nasonova, O., Norgaard, A., Orgeval, T., Ottlé, C., Poccard-Leclercq, I., Polcher, J., Sandholt, I., Saux-Picart, S., Taylor, C. and Xue, Y.: The AMMA Land Surface Model Intercomparison Project (ALMIP), B. Am. Meteorol. Soc., 18651880, 2009.

Brutsaert, W. H.: Evaporation in the Atmosphere - Theory, History, and Applications, Kluwer Academic, D. Reidel publishers, Dordrecht, The Netherlands, 299 pp., 1982.

Carrer, D., Roujean, J.-L., and Meurey, C.: Comparing Operational MSG/SEVIRI Land Surface Albedo Products From Land SAF With Ground Measurements and MODIS, IEEE T. Geosci. Remote, 48, 1714-1728, doi:10.1109/TGRS.2009.2034530, 2010.

Chehbouni, A., Qi, J., Lo Seen, D., Kerr, Y. H., Dedieu, G., Moran, S., Daubas, M., and Monteny, B. M.: Estimation of real evaporation, in: Proc. Int. workshop on Remote Sensing and Water Resources, Montpellier, France, 30 November 1996, Montpellier, 10 pp., 1996.

Courault, D., Seguin, B., and Olioso, A.: Review on estimation of evapotranspiration from remote sensing data: from empirical to numerical modelling approaches, Irrigation and Drainage Systems, 19, 223-249, 2005.

Dolman, A. J., Moors, E. J., Elbers, J. A., and Snijders, W.: Evaporation and surface conductance of three temperate forests in the Netherlands, Ann. For. Sci., 55, 255-270, 1998.

Dolman, A. J. and De Jeu, R. A. M.: Evaporation in focus, Nat. Geosci., 3, 296, doi:10.1038/ngeo849, 2010.

Drusch, M., Scipal, K., de Rosnay, P., Balsamo, G., Andersson, E., Bougeault, P., and Viterbo, P.: Towards a Kalman Filter based soil moisture analysis system for the operational ECMWF 
Integrated Forecast System, Geophys. Res. Lett., 36, L10401, doi:10.1029/2009GL037716, 2009.

Geiger, B., Carrer, D., Franchistéguy, L., Roujean, J.-L., and Meurey, C.: Land Surface Albedo derived on a daily basis from Meteosat Second Generation Observations, IEEE T. Geosci. Remote, 46 (11), 3841-3856, 2008a.

Geiger, B., Meurey, C., Lajas, D., Franchistéguy, L., Carrer, D., and Roujean, J.-L.: Near real time provision of downwelling shortwave radiation estimates derived from satellite observations, Meteorol. Appl., 15 (3), 411-420, 2008 b.

Gellens-Meulenberghs, F.: Sensitivity Tests of an Energy Balance Model to Choice of Stability Functions and Measurement Accuracy, Bound.-Lay. Meteorol., 115 (3), 453-471, 2005.

Gellens-Meulenberghs, F., Arboleda, A., and Ghilain, N.: Towards a continuous monitoring of evapotranspiration based on MSG data, in: Remote Sensing for Environmental Monitoring and Change Detection, edited by: Owe, M. and Neale Ch., IAHS Publ. 316, 228-234, 2007.

Gentine, P., Entekhabi, D., Chehbouni, A., Boulet, G., and Duchemin, B.: Analysis of evaporative fraction diurnal behaviour, Agr. Forest Meteorol., 143, 12-29, 2007.

Goulden, M. L., Miller, S. D., da Rocha, H. R., Menton, M. C., de Freita, H. C., Figueira, A. M. E. S., and de Sousa, C. A. D.: Diel and seasonal patterns of tropical forest $\mathrm{CO} 2$ exchange, Ecol. Appl., 14 (4), 42-54, 2004.

Granier, A., Biron, P., and Lemoine, D.: Water balance, transpiration and canopy conductance in two beech stands, Agr. Forest Meteorol., 100, 291-308, 2000.

Ineichen, P., Barroso, C. S., Geiger, B., Hollmann, R., Marsouin, A., and Mueller, R.: Satellite Application Facilities irradiance products: hourly time step comparison and validation over Europe, Int. J. Remote Sens., 30, doi:0.1080/01431160802680560, 2009.

Jarvis, P. G.: The interpretation of the variations in leaf water potential and stomatal conductance found in canopies in the field, Phil. Trans. Roy. Soc. London B273, 593-610, 1976.

Jiménez, C., Prigent, C., and Aires, F.: Towards an estimation of global land surface heat fluxes from multisatellite observations, J. Geophys. Res., 114, D06305, doi:10.1029/2008JD011392, 2009.

Joffre, R., Rambal, S., and Romane, F.: Local variations of ecosystem functions in a Mediterranean evergreen oak woodland, Ann. For. Sci., 53, 561-570, 1996.

Kalma, J. D., McVicar, T. R., and McCabe, M. F.: Estimating Land Surface Evapotranspiration: A Review of Methods Using Remotely Sensed Surface Temperature Data, Surv. Geophys., 29 (4-5), 2008

Knohl, A., Schulze, A.-D., Kolle, O., and Buchmann, N.: Large carbon uptake by an unmanaged 250-year-old deciduous forest in Central Germany, Agr. Forest Meteorol., 118, 151-167, 2003.

Lhomme, J.-P. and Elguero, E.: Examination of evaporative fraction diurnal behaviour using a soil-vegetation model coupled with a mixed-layer model, Hydrol. Earth Syst. Sci., 3, 259-270, doi:10.5194/hess-3-259-1999, 1999.

Li, Z.-L., Tang, R., Wan, Z., Bi, Y., Zhou, C., Tang, B., Yan, G., and Zhang, X.: A review of current methodologies for regional evapotranspiration estimation from remotely sensed data, Sensors, 9, 3801-3853, doi:10.3390/s90503801, 2009.

LSA-SAF: Product User Manual - Evapotranspiration (ET), (PUM_MET/2.2); 33 pp., available at: http://landsaf.meteo.pt/,
2010.

Masson, V., Champeaux, J. L., Chauvin, F., Meriguet, Ch., and Lacaze, R. A.: Global database of land surface parameters at 1-km resolution in meteorological and climate models, J. Climate, 16 (9), 1261-1282, 2003.

Merbold, L., Ardö, J., Arneth, A., Scholes, R. J., Nouvellon, Y., de Grandcourt, A., Archibald, S., Bonnefond, J. M., Boulain, N., Brueggemann, N., Bruemmer, C., Cappelaere, B., Ceschia, E., El-Khidir, H. A. M., El-Tahir, B. A., Falk, U., Lloyd, J., Kergoat, L., Le Dantec, V., Mougin, E., Muchinda, M., Mukelabai, M. M., Ramier, D., Roupsard, O., Timouk, F., Veenendaal, E. M., and Kutsch, W. L.: Precipitation as driver of carbon fluxes in 11 African ecosystems, Biogeosciences, 6, 1027-1041, doi:10.5194/bg-6-1027-2009, 2009.

Meyers, T. P. and Hollinger, S. E.: An assessment of storage terms in the surface energy balance of maize and soybean, Agr. Forest Meteorol., 125 (1-2), 105-115, 2004.

Miglietta, F., Gioli, B., Brunet, Y., Hutjes, R. W. A., Matese, A., Sarrat, C., and Zaldei, A.: Sensible and latent heat flux from radiometric surface temperatures at the regional scale: methodology and evaluation, Biogeosciences, 6, 1975-1986, doi:10.5194/bg-6-1975-2009, 2009.

Mu, Q., Heinsch, F., Zhao, M., and Running, S. W.: Development of a global evapotranspiration algorithm based on MODIS and global meteorology data, Remote Sens. Environ., 111, 519-536, doi:10.1016/j.rse.2007.04.015, 2007.

Nash, J. E. and Suttcliffe, J. V.: River Flow Forecasting through Conceptual Models, Part I-A Discussion of Principles, J. Hydrol., 10, 282-290, 1970.

Pereira, J. S., Mateus, J. A., Aires, L. M., Pita, G., Pio, C., David, J. S., Andrade, V., Banza, J., David, T. S., Paço, T. A., and Rodrigues, A.: Net ecosystem carbon exchange in three contrasting Mediterranean ecosystems the effect of drought, Biogeosciences, 4, 791-802, doi:10.5194/bg-4-791-2007, 2007.

Porté, A., Bosc, A., Champion, I., and Loustau, D.: Estimating the foliage area of Maritime pine (Pinus Pinaster Ait) branches and crown with application to modeling the foliage area distribution in the crown, Ann. For. Sci., 57, 73-86, 2000.

Rebmann, C., Zeri, M., Lasslop, G., Mund, M., Kolle, O., Schulze, E.-D., and Feigenwinter, C.: Treatment and assessment of the CO2-exchange at a complex forest site in Thuringia, Germany, Agr. Forest Meteorol., 150 (5), 684-691, 2010.

Rodell, M., Houser, P. R., Jambor, U., Gottschalck, J., Mitchell, K., Meng, C.-J., Arsenault, K., Cosgrove, B., Radakovich, J., Bosilovich, M., Entin, J. K., Walker, J. P., Lohmann, D., and Toll, D.: The Global Land Data Assimilation System, B. Am. Meteorol. Soc., 85(3), 2004.

Rosema, A.: Using METEOSAT for operational evapotranspiration and biomass monitoring in the Sahel region, Remote Sens. Environ., 46 (1), 27-44, 1993.

Stisen, S., Sandholt, I., Norgaard, A., Fensholt, R., and Jensen, K. H.: Combining the triangle method with thermal inertia to estimate regional evapotranspiration - Applied to MSG-SEVIRI data in the Senegal River basin, Remote Sens. Environ., 112, 12421255, doi:10.1016/j.rse.2007.08.013, 2008.

Stöckli, R., Lawrence, D. M., Niu, G.-Y., Oleson, K. W., Thornton, P. E., Yang, Z.-L., Bonan, G. B., Denning, A. S., and Running, S. W.: Use of FLUXNET in the Community Land Model development, J. Geophys. Res., 113 (G1), G01025, 
doi:10.1029/2007JG000562, 2008.

Su, Z.: The Surface Energy Balance System (SEBS) for estimation of turbulent heat fluxes, Hydrol. Earth Syst. Sci., 6, 85-100, doi:10.5194/hess-6-85-2002, 2002.

Su, H., Wood, E. F., McCabe, M. F., and Su, Z.: Evaluation of remotely sensed evapotranspiration over the CEOP EOP-1 reference sites, J. Meteorol. Soc. Jpn., 85A, 439-459, 2007.

Su, Z., Dorigo, W., Fernández-Prieto, D., Van Helvoirt, M., Hungershoefer, K., de Jeu, R., Parinussa, R., Timmermans, J., Roebeling, R., Schröder, M., Schulz, J., Van der Tol, C., Stammes, P., Wagner, W., Wang, L., Wang, P., and Wolters, E.: Earth observation Water Cycle Multi-Mission Observation Strategy (WACMOS), Hydrol. Earth Syst. Sci. Discuss., 7, 7899-7956, doi:10.5194/hessd-7-7899-2010, 2010.

Teuling, A. J., Hirschi, M., Ohmura, A., Wild, M., Reichstein, M., Ciais, P., Buchmann, N., Ammann, C., Montagnani, L., Richardson, A. D., Wohlfahrt G., and Seneviratne, S. I.: A regional perspective on trends in continental evaporation, Geophys. Res. Lett., 36, L02404, doi:10.1029/2008GL036584, 2009.

Timmermans, J., van der Tol, C., Verhoef, A., Wang, L., van Helvoirt, M., Verhoef, W., and Su, Z.: Quantifying the uncertainty in estimates of surface atmosphere fluxes by evaluation of SEBS and SCOPE models, Proc. 'Earth Observation and Water Cycle Science', Frascati, Italy, 18-20 November 2009, ESA SP674, January 2010.

Trigo, I. F., DaCamara, C. C., Viterbo, P., Roujean, J.-L., Olesen, F., Barroso, C., Camacho-de Coca, F., Carrer, D., Freitas, S. C., Garcia-Haro, J., Geiger, B., Gellens-Meulenberghs, F., Ghilain, N., Melia, J., Pessanha, L., Siljamo, N., and Arboleda, A.: The Satellite Application Facility on Land Surface Analysis, Int. J. Remote Sens., in press, 2011.
Trigo, I. F., Monteiro, I. T., Olesen, F., and Kabsch, E.: An assessment of remotely sensed land surface temperature, J Geophys. Res., 113 (D17), D17108, doi:10.1029/2008JD010035, 2008.

van den Hurk, B. J. J. M., Viterbo, P., Beljaars, A. C. M., and Betts, A. K.: Offline validation of the ERA40 surface scheme, ECMWF Technical Memorandum No. 295, 41 pp., 2000.

Verger, A., Camacho, F., García-Haro, F. J., and Meliá, J.: Prototyping of Land-SAF leaf area index algorithm with VEGETATION and MODIS data over Europe, Remote Sens. Environ., 113, 2285-2297, doi:10.1016/j.rse.2009.06.009, 2009.

Viterbo, P. and Beljaars, A. C. M.: An improved land surface parameterization scheme in the ECMWF model and its validation, J. Climate, 8, 2716-2748, 1995.

Wagner, W., Noll, J., Borgeaud, M., and Rott, H.: Monitoring Soil Moisture over the Canadian Prairies with the ERS Scatterometer, IEEE T. Geosci. Remote, 37, 206-216, 1999.

Wang, K., Wang, P., Li, Z., Sparrow, M., and Cribb, M.: A simple method to estimate evapotranspiration from a combination of net radiation, vegetation indices and temperatures, J. Geophys. Res., 112, D15107, doi:10.1029/2006JD008351, 2007.

Wilson, K. B., Goldstein, A. H., Falge, E., Aubinet, M., Baldocchi, D., Berbigier, P., Bernhofer, Ch., Ceulemans, R., Dolman, H., Field, C., Grelle, A., Law, B., Meyers, T., Moncrieff, J., Monson, R., Oechel, W., Tenhunen, J., Valentini, R., and Verma, S.: Energy balance closure at FLUXNET sites, Agr. Forest Meteorol., 113, 223-243, 2002.

Wood, E. F., Jimenez, C., Seneviratne, S. I., and McCabe, M.: Satellite-based retrievals of global evapotranspiration, and a report on the GEWEX Landflux initiative, Proc. 'Earth Observation and Water Cycle Science', Frascati, Italy, 18-20 November 2009 ESA SP-674, 2010. 